\title{
Lateral retroperitoneoscopic adrenalectomy for complicated adrenal tumor larger than 5 centimeters.
}

\author{
Wei Chen, Wei Lin, Deng-Jun Han, Yong Liang
}

Department of Urology, Zigong Fourth People's Hospital, Sichuan, China, 643000

\begin{abstract}
Background: The role of lateral retroperitoneoscopic adrenalectomy (LRA) for complicated tumor with large diameter remains controversial, this study aimed to evaluate the effectiveness of this procedure on the management of tumor larger than $5 \mathrm{~cm}$ in diameter.

Methods: A retrospective comparison was conducted of 67 patients with large complicated adrenal tumor ( $>5 \mathrm{~cm}) .41$ patients received LRA, and 26 received open adrenalectomy (OA) in our hospital between January 2011 and June 2015. Basic characteristics regarding mean age, gender, body mass index (BMI), tumor size, tumor side, previous abdominal surgery, resection method, pathology were preferentially analyzed. Operative indicators regarding operation time, estimated blood loss (EBL), conversion to ICU, complications, post-operative hospitalization, duration of drain, time to first oral intake and ambulation were compared between groups.

Results: There were no significant differences between the two groups in the basic characteristics. The mean operation time for

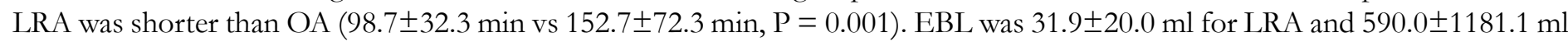
for OA $(\mathrm{P}=0.03)$. There was no complication in LRA group and one patient in OA group had complications, but this difference was not significant $(\mathrm{P}=\mathrm{NS})$. The post-operative hospitalization in LRA was $7.4 \pm 2.8$ days, and shorter than $9.8 \pm 2.7$ days in $\mathrm{OA}$ group $(\mathrm{P}=0.00)$. The time to first oral intake and ambulation for LRA was shorter than OA (first oral intake, $1.9 \pm 0.8$ days vs $3.1 \pm 1.3$ days, $\mathrm{P}=0.00$; time to ambulation, $2.6 \pm 1.4$ days vs $4.2 \pm 1.6$ days, $\mathrm{P}=0.00)$. While the difference between groups were not significant in terms of ICU conversion (3/41 vs 4/26, P $=$ NS) and duration of drain (3.9 \pm 2.2 days vs $4.7 \pm 1.9$ days, $\mathrm{P}=\mathrm{NS})$. Conclusion: Our study shows that LRA can be performed safely and effectively for complicated adrenal tumors larger than 5 $\mathrm{cm}$ in diameter, but it remains technically demanding.
\end{abstract}

Keywords: Retroperitoneoscopic adrenalectomy; adrenal tumor; lateral position.

DOI: https://dx.doi.org/10.4314/ahs.v17i1.36

Cite as: Chen W, Lin W, Han D-J, Liang Y. Lateral retroperitoneoscopic adrenalectomy for complicated adrenal tumor larger than 5 centimeters. Afri Health Sci. 2017;17(1): 293-300. https://dx.doi.org/10.4314/ahs.v17i1.36

\section{Introduction}

Since the endoscopic technique was first introduced to perform adrenalectomy in $1992^{1}$, several approaches of laparoscopic adrenalectomy have been widely used in the treatment of the vast majority of benign adrenal tumors $^{2-6}$. Among the various approaches, the retroperitonoscopy was widely accepted due to the direct vision. While due to the limited space of posterior peritoneum, the indications of this approach was also confined to small adrenal tumors.

\footnotetext{
Corresponding author:

Yong Liang,

Department of Urology,

Zigong Fourth People's Hospital, Sichuan, China,

Email: urologyly@163.com
}

Satisfactory clinical results of lateral retroperitoneoscopic adrenalectomy (LRA) have been reported in small adrenal tumors $^{7-9}$, while there is a paucity of data on the large or malignant adrenal tumors ${ }^{10}$. In the last decades of $20^{\text {th }}$ century, Henry ${ }^{11}$ presented a successful case series of patients who received retroperitoneoscopic adrenalectomy, with potential malignant and large diameter adrenal tumors. However, different opinion has existed in some surgeons. Due to the narrow working space, many scholars tend to choose an open or transperitoneal approach to deal with large adrenal tumors ${ }^{12-14}$.

The aim of this study was to compare the operative outcome of LRA versus open surgery in the treatment of patients with large diameter $(\geq 5 \mathrm{~cm})$ complicated adrenal tumors. 


\section{Patients and methods}

The prospectively maintained urology database in the department of urology at Zigong No.4 people's hospital was retrospectively reviewed to collect data on the large diameter complicated adrenal tumor patients who underwent LRA or open surgery, from January 2011 to June 2015. There were 67 patients with adrenal tumor larger than $5 \mathrm{~cm}$. Of the 67 cases, 41 (26 male and 15 female) underwent LRA and the other 26 (13 male and $13 \mathrm{fe}-$ male) underwent open procedure. All of the patients received complete laboratory examination, which involved plasma metanephrines, aldosterone, renin and the aldosterone/renin ratio (ARR), vanilmandelic acid (VMA), 17-hydroxycorticosteroids (17-OHCS), and 17-keto-steroid (17-KS). Image evaluations such as computed tomography (CT) were used to determine the localization and diameter of adrenal mass. Open surgery was used in patients with local lymph invasion or periadrenal involvement according to the radiographic evidence. All of the patients were provided operative informed consent, which mentioned the benefits and potential risks of proposed operation method. For patients proposed to LRA, we also informed them that the open conversion might be chosen once any difficulties were encountered during the operation.

\section{Surgical technique}

According to the different surgical methods, all the patients were divided into LRA group and open adrenalectomy group (OA). A 30-degree laparoscope was used as observation mirror though a $10 \mathrm{~mm}$ trocar, the other two trocars were located in anterior axillary line and posterior axillary line of subcostal space with a diameter in $5 \mathrm{~mm}$ or $10 \mathrm{~mm}$ (Figure 1).

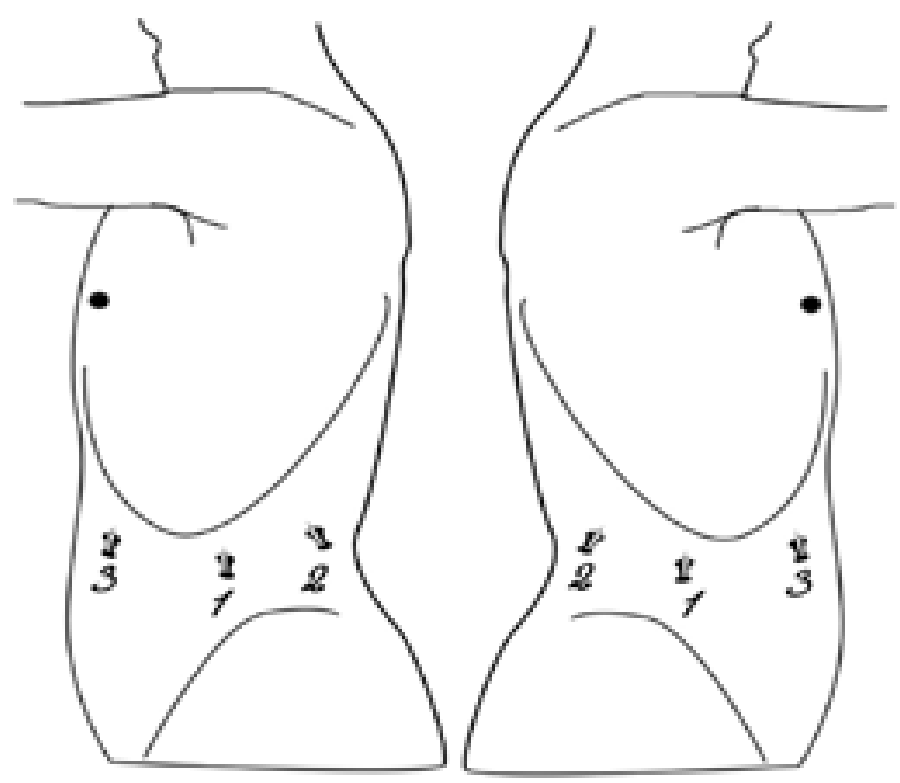

Figure 1. Trocar port placement: (1) $10 \mathrm{~mm}$ port for camera, (2) and (3) $5 \mathrm{~mm}$ port for forceps manipulators.

Ultrasonic shears were used to divide and identify the edge of adrenal gland. The adrenal central vein was divided between hem-o-lok clips. After the adrenal was dissected completely, a self-made bag was used to dress up the adrenal gland via a $10 \mathrm{~mm}$ trocar into the peritoneal cavity. The mass was cut and examined on the operation table to ensure the entire tumor was involved. If it is necessary, a hand-assisted retroperitonoscopic adrenalectomy (HARA) was used in the LRA group, which was placed at the intersection of mid-axillary line and subcostal area (Figure 2). 


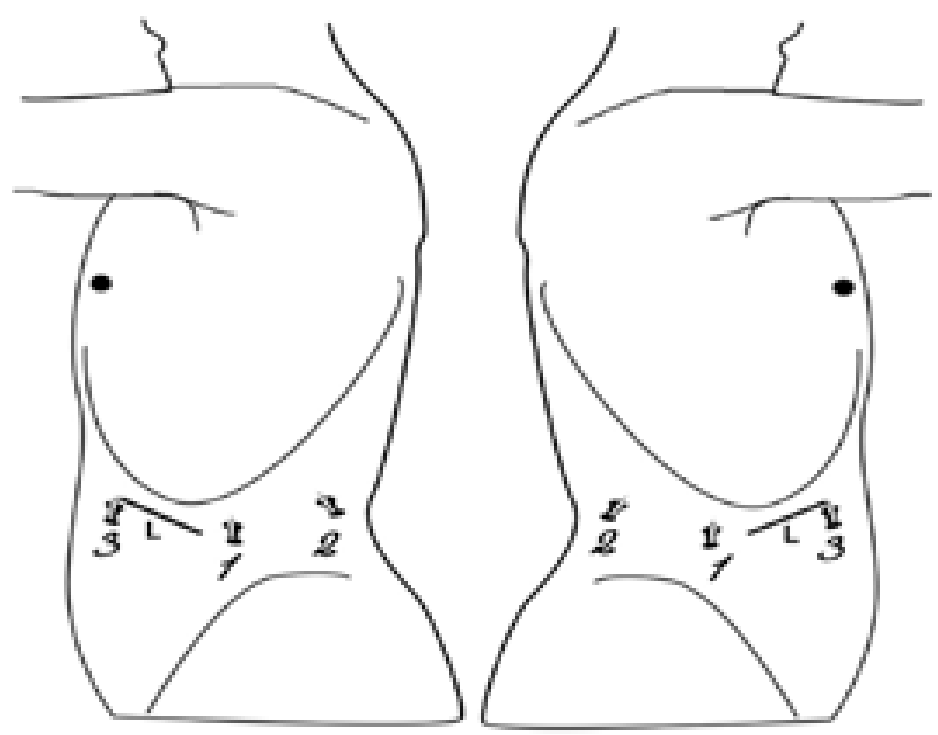

Figure 2. The incision was marked as "L" for hand-assisted retroperitonoscopic adrenalectomy.

After the adrenal area was exposed, special attention would be given to evaluate the tumor location and whether there is periadrenal involvement. In both the LRA and OA group, the main principle was resection with as much peri-adrenal tissue as possible to ensure the highest negative margin rate. Drainage tube was routinely placed before operation was complete. All the procedures were performed by senior experienced laparoscopic surgeons to reduce the selective bias.

\section{Post-operative management}

Routinely, the patients were put in the post-anesthesia care unit (PACU) until the blood pressure and heart rate were stable, and the patients had regained consciousness after surgery. Patients with significant bleeding or labile blood pressure were converted to intensive care unit (ICU). After approximately thirty minutes' post-operative monitoring in PACU, patients were transferred to urology department for half to one day's electrocardiography monitoring. 24 hours to two days' fasting was needed to help the bowel function recovery. During this period, post-operative intravenous fluid supplement was used in all the patients. Post-operative hypotension would be timely corrected, and this could have been caused by the bleeding or inadequate intravenous fluids supplement during the intra- or post-operative; fortunately, there was no patient who required this management. Patients were discharged after adequate pain control and the drainage tube was extubated. In addition, patients received regular diet and normal ambulation as regards to the requirement condition to achieve discharge standard.

\section{Outcome definition}

To evaluate the efficacy of LRA and OA, both the intra-operative terms and post-operative terms were needed. The intra-operative terms included; operation time, estimated blood loss (EBL), complications and number of ICU conversions. The post-operative terms included; hospitalization, duration of drain, time to first oral intake and time to first ambulation.

Additionally, basic characteristics was preferentially analyzed to assess the balance and comparability between two groups, which covered mean age, gender, body mass index (BMI), tumor size, tumor side, previous abdominal surgery, resection method and pathology type.

\section{Statistical analysis}

All the continuous data was expressed as mean \pm standard deviation; discontinuous data was presented as percentage. Statistical analyses were performed using SPSS version 20.0 (SPSS Inc, Chicago, IL). Two independent sample $t$ tests were used in the continuous variables, and the Chi-square tests were used in the discontinuous variables. Curve estimations were used to explore the correlation between diameter and other potential factors. The estimating model included linear, logarithmic, inverse, quadratic, cubic, compound, power, s curve, growth curve and exponential. $\mathrm{P}<0.05$ was regarded as the difference between significant groups.

\section{Results}

\section{Basic characteristics}

Sixty seven adrenalectomies were performed between 
January 2011 and June 2015 at Zigong No.4 people's hospital. Of these, 41 patients underwent LRA and 26 patients underwent $\mathrm{OA}$. The mean age for all cases was $42.3 \pm 13.9$ years and there were $39(58.2 \%)$ males. The mean tumor size was $6.9 \pm 2.7 \mathrm{~cm}$. Tumor localization and peritoneal invasion of each patient was previously evaluated by CT scan. There were 40 cases $(59.7 \%)$ of left localization of tumor, and tumors in two cases $(2.99 \%)$ were bilateral. Of the patients, 49 cases $(73.1 \%)$ had the diagnosis of aldosterone-producing adenoma or adrenocortical hyperplasia, 7 cases $(10.4 \%)$ had the diagnosis of pheochromocytoma. There were 3 cases $(4.5 \%)$ of hematoma and adrenal cyst. In the case series, there was 1 adrenocortical carcinoma (ACC) of LRA and 2 ACC of OA. Because this type of adrenal tumor is considered a malignant mass, the ACC in LRA group was converted to HARA. The remaining two cases were respectively diagnosed as adrenal medullary hyperplasia and myelolipoma. Total adrenalectomies were performed in 41 cases $(61.2 \%)$. There were no significant differences between the two groups in all the basic characteristics $(\mathrm{P}>0.05)$. Table 1 depicts the difference of basic characteristics between groups.

Table 1. Basic characteristics comparison between groups.

\begin{tabular}{|c|c|c|c|c|}
\hline & Total & LRA & $\mathbf{O A}$ & $P$ value \\
\hline No. of patients & 67 & 41 & 26 & \\
\hline Mean age (yrs) & $42.3 \pm 13.9$ & $44.4 \pm 38.9$ & $39.1 \pm 15.6$ & 0.13 \\
\hline BMI $\left(\mathrm{kg} / \mathrm{m}^{2}\right)$ & $23.3 \pm 2.1$ & $23.5 \pm 2.4$ & $22.7 \pm 1.6$ & 0.08 \\
\hline Tumor size $(\mathrm{cm})$ & $6.9 \pm 2.7$ & $5.8 \pm 1.1$ & $7.6 \pm 2.4$ & 0.56 \\
\hline Gender & & & & 0.28 \\
\hline Male & 39 & 26 & 13 & \\
\hline Female & 28 & 15 & 13 & \\
\hline Localization & & & & 0.07 \\
\hline Left & 40 & 29 & 41 & \\
\hline Right & 25 & 11 & 14 & \\
\hline Bilateral & 2 & 1 & 1 & \\
\hline Previous abdominal surgery & 1 & 1 & 0 & 0.42 \\
\hline Resection & & & & 0.33 \\
\hline Total & 41 & 27 & 14 & \\
\hline Partial & 26 & 14 & 12 & \\
\hline Pathology & & & & 0.31 \\
\hline Adrenocortical hyperplasia & 23 & 10 & 13 & \\
\hline Aldosterone-producing adenoma & 26 & 18 & 8 & \\
\hline Adrenal medullary hyperplasia & 1 & 1 & 0 & \\
\hline Adrenal myelolipoma & 1 & 1 & 0 & \\
\hline Adrenocortical carcinoma & 3 & 2 & 1 & \\
\hline Adrenal cyst & 3 & 3 & 0 & \\
\hline Hematoma & 3 & 1 & 2 & \\
\hline Pheochromocytoma & 7 & 5 & 2 & \\
\hline
\end{tabular}

BMI, body mass index; LRA, retroperitoneoscopic adrenalectomy; $\mathbf{O A}$, open adrenalectomy

\section{Operative terms comparison}

Table 2 lists details on operative variables of two groups. The mean operation time for LRA was $98.7 \pm 32.3$ min, while this time in OA group was $152.7 \pm 72.3 \mathrm{~min}$, the difference between the groups was significant $(\mathrm{P}=0.001)$. Estimated blood loss (EBL) was $31.9 \pm 20.0 \mathrm{ml}$ for LRA and $590.0 \pm 1181.1 \mathrm{ml}$ for $\mathrm{OA}(\mathrm{P}=0.03)$. There was no complication in LRA group, while one patient in OA group had high fever after operation, and the temperature dropped to normal after use of antibiotics. The differ- ence of complication was not significant $(\mathrm{P}=\mathrm{NS})$. The post-operative hospitalization in LRA was $7.4 \pm 2.8$ days, and this was shorter than 9.8 \pm 2.7 days in OA group $(\mathrm{P}=$ $0.00)$. The time to first oral intake and ambulation for LRA was shorter than OA (first oral intake, $1.9 \pm 0.8$ days vs $3.1 \pm 1.3$ days, $\mathrm{P}=0.00$; time to ambulation, $2.6 \pm 1.4$ days vs $4.2 \pm 1.6$ days, $\mathrm{P}=0.00$ ). While the difference between groups were not significant in terms of ICU conversion $(3 / 41$ vs $4 / 26, \mathrm{P}=\mathrm{NS})$ and duration of drain (3.9 \pm 2.2 days vs $4.7 \pm 1.9$ days, $\mathrm{P}=\mathrm{NS}$ ).

Table 2. Operative and postoperative outcomes comparison between groups

\begin{tabular}{|l|c|c|c|c|}
\hline & Total & LRA & OA & P value \\
\hline No. of patients & 67 & 41 & 26 & \\
Convert to ICU & 7 & 3 & 4 & 0.42 \\
Complication & 1 & 0 & 1 & 0.39 \\
Operation time & $121.9 \pm 60.9$ & $98.7 \pm 32.3$ & $152.7 \pm 72.3$ & 0.001 \\
Estimated blood loss & $418.8 \pm 125.9$ & $31.9 \pm 20.0$ & $590.0 \pm 118.1$ & $<0.001$ \\
Hospitalization & $8.3 \pm 3.0$ & $7.4 \pm 2.8$ & $9.8 \pm 2.7$ & $<0.001$ \\
Duration of drain & $4.2 \pm 2.1$ & $3.9 \pm 2.2$ & $4.7 \pm 1.9$ & 0.18 \\
First oral intake & $2.4 \pm 1.2$ & $1.9 \pm 0.8$ & $3.1 \pm 1.3$ & $<0.001$ \\
Time to ambulation & $3.2 \pm 1.7$ & $2.6 \pm 1.4$ & $4.2 \pm 1.6$ & $<0.001$ \\
\hline
\end{tabular}

ICU, intensive care unit; LRA, retroperitoneoscopic adrenalectomy; OA, open adrenalectomy 


\section{Correlation of diameter and operation variables}

We performed the curve estimation to investigate the correlation of diameter and each operation variable. The result presented that tumor diameter was positively correlation with estimated blood loss $(\mathrm{R}=0.68, \mathrm{P}<0.01)$, operation time $(\mathrm{R}=0.46, \mathrm{P}=0.00)$ and duration of drain $(\mathrm{R}=0.26, \mathrm{P}=0.04)$ in the estimating model. However, the tumor diameter was not associated with the hospitalization, time to ambulation and first oral intake $(\mathrm{P}>0.05)$. Table 3 summarizes the adjusted correlation index and its $P$ value of entire estimation.

Table 3. Correlation between diameter and each operation variable

\begin{tabular}{|l|c|c|c|}
\hline \multicolumn{1}{|c|}{ Variable } & $\mathbf{R}^{2}$ & $\mathbf{R}$ & $\boldsymbol{P}$ value \\
\hline Operation time & 0.21 & 0.46 & $<0.001$ \\
Estimated blood loss & 0.46 & 0.68 & $<0.001$ \\
Hospitalization & 0.01 & 0.12 & 0.41 \\
Duration of drain & 0.07 & 0.26 & 0.04 \\
Fist oral intake & 0.01 & 0.11 & 0.25 \\
Time to ambulation & 0.01 & 0.09 & 0.19 \\
\hline
\end{tabular}

$\mathbf{R}^{2}$, adjusted coefficient of determination; $\mathbf{R}$, adjusted correlation index

Studies on laparoscopic adrenalectomy versus open procedure

We also retrieved studies that focused on the laparoscopic adrenalectomy (LA) for large adrenal tumors. A total of 9 studies ${ }^{15-24}$ mentioned the comparison on LA and $\mathrm{OA}$, and two studies ${ }^{25,26}$ mentioned different diameter of adrenal tumor in LA. There exists controversy on the advantages of laparoscopy, as shown in the summarized information of related studies listed in Table 4.

Table 4 Studies on the laparoscopic adrenalectomy for tumors larger than $5 \mathrm{~cm}$

\begin{tabular}{|c|c|c|c|c|}
\hline Fisrt Author & Year & Origin country & Patients $^{\dagger}$ & Compare outcome \\
\hline Brix & 2010 & Germany & $\begin{array}{l}\text { OA } 117 \\
\text { Lap } 35\end{array}$ & Lap is not inferior to $\mathrm{OA}$ for adrenal tumor $\leq 10 \mathrm{~cm}$ \\
\hline Poripiglia & 2010 & Italy & $\begin{array}{l}\text { OA } 25 \\
\text { Lap } 18\end{array}$ & No differences in terms of survival time were noted \\
\hline Miller & 2010 & USA & $\begin{array}{l}\text { OA } 71 \\
\text { Lap } 17\end{array}$ & Lap is inferior to OA for adrenal tumor \\
\hline Mir & 2012 & USA & $\begin{array}{l}\text { OA } 26 \\
\text { Lap } 18\end{array}$ & Lap is inferior to OA for adrenal tumor \\
\hline Gonzalez & 2005 & USA & $\begin{array}{l}\text { OA } 133 \\
\text { Lap } 6 \\
\text { Lap } \geq 8 \mathrm{~cm}\end{array}$ & Lap is inferior to OA for adrenal tumor \\
\hline Bozkurt & 2015 & Turkey & $\begin{array}{l}\text { Lap }<8 \mathrm{~cm} \\
\text { Lap } \geq 5 \mathrm{~cm}\end{array}$ & LA is safe and effective for adrenal tumor $<15 \mathrm{~cm}$ \\
\hline Feo & 2015 & Italy & $\begin{array}{l}\text { Lap }<5 \mathrm{~cm} \\
\text { Lap } \geq 8 \mathrm{~cm}\end{array}$ & $\geq 5 \mathrm{~cm}$ prolonged hospital stay (HR $0.67 ; 95 \%$ CI $0.47-0.97$ ) \\
\hline Feo & 2015 & Italy & Lap $<8 \mathrm{~cm}$ & $\geq 8 \mathrm{~cm}$ prolonged operative time (HR $0.47 ; 95 \%$ CI $0.24-0.94)$ \\
\hline Donatini & 2014 & France & $\begin{array}{l}\text { OA } 21 \\
\text { Lap } 13\end{array}$ & Lap is not inferior to OA for adrenal tumor $\leq 10 \mathrm{~cm}$ \\
\hline Cooper & 2013 & USA & $\begin{array}{l}\text { OA } 46 \\
\text { Lap } 46\end{array}$ & Lap is inferior to OA for adrenal tumor \\
\hline Fossa & 2013 & Norway & $\begin{array}{l}\text { OA } 15 \\
\text { Lap } 17\end{array}$ & $\begin{array}{l}\text { Lap is inferior to OA in short-term and similar with } O A \text { in long-term } \\
\text { for adrenal tumor }\end{array}$ \\
\hline Lombardi & 2012 & Italy & $\begin{array}{l}\text { OA } 126 \\
\text { Lap } 30\end{array}$ & Lap is not inferior to OA for adrenal tumor \\
\hline Levoulleux & 2010 & France & $\begin{array}{l}\text { OA } 58 \\
\text { Lap } 6\end{array}$ & Lap is inferior to OA for adrenal tumor \\
\hline
\end{tabular}

$\uparrow$ OA, Open adrenalectomy; Lap, Laparoscopic adrenalectomy

\section{Discussion}

Adrenal surgery has been a high-risk operation in urology for a long time. Due to the special location of the adrenals, even when dealing with a small diameter adrenal tumor, it needs a large incision and high position to carry out the operation ${ }^{27}$. This method has not only caused great trauma to patients, but also significantly improves the proportion of pleural lesions and surgical complica- 
tions. Most important adrenal vasculature can only be ligated through blind separation and hand feeling for the reason that most adrenals could show difficulties; this increased the probability of tissue injury and hemorrhage ${ }^{28}$. Laparoscopic adrenal surgery could be a finer and convenient operation. It can clearly separate the important vessels under a direct vision. This technique can significantly decrease the post-operative complications ${ }^{29}$.

There are many methods of minimally invasive surgeries in the management of adrenal tumors. According to the different surgical approaches, they can be divided into transperitoneal and retroperitoneal laparoscopy adrenalectomy $\left(\right.$ RLA) ${ }^{30}$. Advantages and disadvantages have been reported on the transperitoneal and retroperitoneal adrenalectomy. The transperitoneal approach can benefit from more visibility and larger working space, as well as most familiar anatomy for surgeons. Previous opinion shows that TLA is better than RLA in the treatment of large adrenal tumors $(>5 \mathrm{~cm})$. However, in TLA, there is need to mobilize intra-abdominal structures and organs, which has a high risk for organ or vascular injury. The complications of TLA also include prolonged ileus and the risk of adhesion formation. In the treatment of patients who received previous abdominal surgery, the TLA is especially difficult to perform. While RLA owns obvious advantages, as it has a more direct route and doesnot interfere with the intra-abdominal organs. In our previous research, we identified that the operative time in RLA is shorter than $\mathrm{TLA}^{30}$. With the development of minimally invasive surgery, scholars constantly show that the large adrenal tumor can also benefit from RLA approach.

In the RLA, we can also divide it in lateral, posterior and anterior approach. Since Zhang el $\mathrm{al}^{31}$ made the lateral retroperitonoscopic adrenalectomy (LRA) promotion and standardization, it has been the most common method in dealing with adrenal tumor in China. In our experience, even though the retroperitoneal approach is difficult, it is beneficial in the post-operative recovery. Since the improvement of laparoscopic instruments and proficiency of operation skill, the tumor diameter may not be the major restricting factor ${ }^{32}$. While, there were discrepant opinions on the application of laparoscope in the management of large $(>5 \mathrm{~cm})$ adrenal tumor ${ }^{33,34}$. The aim of the present study was to compare the results of LRA and OA in the management of large adrenal tumors ( $>$ $5 \mathrm{~cm})$. The results revealed that the LRA was superior to
OA in terms of operation time, intraoperative blood loss, post-operative hospitalization, complication, first oral intake and time to ambulation. There were three patients in LRA group and 4 patients in OA group who converted to ICU. Among these patients, five cases were pheochromocytoma (PHEO), with unstable blood pressure. Abnormal blood vessels and huge volume can always be found in PHEO cases. Additionally, catchecholamines would be overly secreted during the tumor disturbance ${ }^{35}$. Both these features could lead to sharp fluctuations in blood pressure and heart rate, and increase the risk of bleeding. The complication of LRA was around $11.5 \%$, and included adrenal cataclastic, peritoneal injury, vena cava and renal vein injury ${ }^{36}$. In addition, the hypercapnia and pneumoderm which are caused by high pressure of $\mathrm{CO}_{2}$ or the shallowly insertion of Trocar can also happen ${ }^{37}$. Usually, the $\mathrm{CO}_{2}$ insufflation pressure was proper when between 12 and $15 \mathrm{cmH}_{2} \mathrm{O}$ according to our experience. Studies showed that these complications were mainly related with learning curve and different surgeons ${ }^{38,39}$.

Bleeding in LRA will inevitably be less with a small incision and slightly tissue injury. Our experience suggested that we can inject approximately $350 \mathrm{ml}$ normal saline into a self-made gasbag to expand the potential peritoneal cavity. Then followed by 3 minutes' compression in order to prevent the bleeding caused by small blood vessel rupture. In addition, ultrasonic knife could be widely used in the solidification of small blood vessels during the separation of renal fascia and adipose capsule. However, open surgery hemostasis would be chosen without any hesitation when the operating vision was influenced by adrenal cataclastic or unmanageable vascular injury ${ }^{40}$.

\section{Limitations}

There were certain limitations of LRA that we need to take into consideration. The restricted potential cavity limited the diameter of removable tumor. The interaction of surgical instruments could also obviously affect the ease of operation. Many scholars have reported that the retroperitoneal laparoscope could just be used in the small- to medium-sized benign adrenal tumor ${ }^{41}$. However, the evidence from our present study has removed this restriction. Moreover, the normal anatomic marks of peritoneal cavity would be disturbed by the use of gasbag, which was usually used to expand the peritoneal cavity. This may also enhance the difficulty of operation. More importantly, the effect of gas bag extrusion could also 
make the tumor over-secret catchecholamines in PHEO cases, therefore the pre-operative blood pressure and sphygmus control are very important ${ }^{42}$.

In summary, LRA provides a new way of minimally invasive surgery for the surgical treatment of the adrenal disease. It was superior to open surgery in management of large adrenal tumors, in terms of operation time, intraoperative blood loss and post-operative recovery. Our result has strengthened the opinion that there is availability of LRA for adrenal tumor greater than 5 centimeters. Uro-surgeons or endocrinology surgeons could take LRA into consideration when they deal with large adrenal tumors.

\section{Conflict of interest}

None.

\section{Reference}

1. Gagner M, Lacroix A, Bolte E. Laparoscopic adrenalectomy in Cushing's syndrome and pheochromocytoma. N Engl J Med, 1992, 327(14): 1033 PubMed.

2. Kuruba R, Gallagher SF. Current management of adrenal tumors. Current opinion in oncology, 2008, 20(1): 34-46. 3. Agarwal S, Chand G, Agarwal A. Posterior retroperitoneoscopic adrenalectomy for clinical and subclinical Cushing's syndrome. World journal of surgery, 2011, 35(1): 237; author reply 238.

4. Alesina PF, Hommeltenberg S, Meier B, et al. Posterior retroperitoneoscopic adrenalectomy for clinical and subclinical Cushing's syndrome. World Journal of surgery, 2010, 34(6): 1391-1397.

5. Callender GG, Kennamer DL, Grubbs EG, et al. Posterior retroperitoneoscopicadrenalectomy. Advances in surgery, 2009, 43147-157.

6. Perrier ND, Kennamer DL, Bao R, et al. Posterior retroperitoneoscopic adrenalectomy: preferred technique for removal of benign tumors and isolated metastases. Ann Surg, 2008, 248(4): 666-674. PubMed

7. Tobias-Machado M, Rincon Rios F, Tulio Lasmar M, et al. Laparoscopic retroperitoneal adrenalectomy as a minimally invasive option for the treatment of adrenal tumors. Archivos espanoles de urologia, 2006, 59(1): 49-54.

8. Suzuki K. Laparoscopic adrenalectomy: retroperitoneal approach. The Urologic clinics of North America, 2001, 28(1): 85-95.

9. Gasman D, Droupy S, Koutani A, et al. Laparoscopic adrenalectomy: the retroperitoneal approach. J Urol, 1998, 159(6): 1816-1820. PubMed
10. Agha A, von Breitenbuch P, Gahli N, et al. Retroperitoneoscopic adrenalectomy: lateral versus dorsal approach. Journal of surgical oncology, 2008, 97(1): 90-93.

11. Henry JF. Minimally invasive adrenal surgery. Best practice \& research Clinical endocrinology \& metabolism, 2001, 15(2): 149-160. PubMed

12. Scoglio D, Balla A, Pacile M, et al. Laparoscopic transperitoneal anterior adrenalectomy. Annali italiani di chirurgia, 2013, 84411-416.

13. Pedziwiatr M, Matlok M, Kulawik J, et al. Laparoscopic adrenalectomy by the lateral transperitoneal approach in patients with a history of previous abdominal surgery. Wideochirurgia i inne techniki malo inwazyjne = Videosurgery and other miniinvasive techniques / kwartalnik pod patronatem Sekcji Wideochirurgii TChP oraz Sekcji Chirurgii Bariatrycznej TChP, 2013, 8(2): 146-151.

14. Mohammadi-Fallah MR, Mehdizadeh A, Badalzadeh A, et al. Comparison of transperitoneal versus retroperitoneal laparoscopic adrenalectomy in a prospective randomized study. Journal of laparoendoscopic \& advanced surgical techniques Part A, 2013, 23(4): 362-366.

15. Leboulleux S, Deandreis D, Al Ghuzlan A, et al. Adrenocortical carcinoma: is the surgical approach a risk factor of peritoneal carcinomatosis? European journal of endocrinology / European Federation of Endocrine Societies, 2010, 162(6): 1147-1153.

16. Lombardi CP, Raffaelli M, De Crea C, et al. Open versus endoscopic adrenalectomy in the treatment of localized (stage I/II) adrenocortical carcinoma: results of a multi-institutional Italian survey. Surgery, 2012, 152(6): 1158-1164.

17. Fossa A, Rosok BI, Kazaryan AM, et al. Laparoscopic versus open surgery in stage I-III adrenocortical carcinoma -- a retrospective comparison of 32 patients. Acta oncologica, 2013, 52(8): 1771-1777. PubMed

18. Cooper AB, Habra MA, Grubbs EG, et al. Does laparoscopic adrenalectomy jeopardize oncologic outcomes for patients with adrenocortical carcinoma? Surgical endoscopy, 2013, 27(11): 4026-4032. PubMed

19. Donatini G, Caiazzo R, Do Cao C, et al. Long-term survival after adrenalectomy for stage I/II adrenocortical carcinoma (ACC): a retrospective comparative cohort study of laparoscopic versus open approach. Annals of surgical oncology, 2014, 21(1): 284-291.

20. Mir MC, Klink JC, Guillotreau J, et al. Comparative outcomes of laparoscopic and open adrenalectomy for adrenocortical carcinoma: single, high-volume center experience. Annals of surgical oncology, 2013, 20(5): 14561461.

African Health Sciences Vol 17 Issue 1, March, 2017 
21. Miller BS, Ammori JB, Gauger PG, et al. Laparoscopic resection is inappropriate in patients with known or suspected adrenocortical carcinoma. World Journal of surgery, 2010, 34(6): 1380-1385.

22. Porpiglia F, Fiori C, Daffara F, et al. Retrospective evaluation of the outcome of open versus laparoscopic adrenalectomy for stage I and II adrenocortical cancer. European urology, 2010, 57(5): 873-878. PubMed

23. Brix D, Allolio B, Fenske W, et al. Laparoscopic versus open adrenalectomy for adrenocortical carcinoma: surgical and oncologic outcome in 152 patients. European urology, 2010, 58(4): 609-615. PubMed

24. Gonzalez RJ, Shapiro S, Sarlis N, et al. Laparoscopic resection of adrenal cortical carcinoma: a cautionary note. Surgery, 2005, 138(6): 1078-1085; discussion 10851076. PubMed

25. Bozkurt IH, Arslan M, Yonguc T, et al. Laparoscopic adrenalectomy for large adrenal masses: Is it really more complicated? The Kaohsiung Journal of Medical Sciences, 2015, 31(12): 644-648.

26. Feo CV, Portinari M, Maestroni U, et al. Applicability of laparoscopic approach to the resection of large adrenal tumours: a retrospective cohort study on 200 patients. Surgical endoscopy, 2015, Epub ahead of print.

27. Eichhorn-Wharry LI, Talpos GB, Rubinfeld I. Laparoscopic versus open adrenalectomy: another look at outcome using the Clavien classification system. Surgery, 2012, 152(6): 1090-1095. PubMed

28. Wang HS, Li CC, Chou YH, et al. Comparison of laparoscopic adrenalectomy with open surgery for adrenal tumors. The Kaohsiung Journal of Medical Sciences, 2009, 25(8): 438-444.

29. Boylu U, Oommen M, Lee BR, et al. Laparoscopic adrenalectomy for large adrenal masses: pushing the envelope. Journal of endourology / Endourological Society, 2009, 23(6): 971-975.

30. Chen W, Li F, Chen D, et al. Retroperitoneal versus transperitoneal laparoscopic adrenalectomy in adrenal tumor: a meta-analysis. Surg Laparosc Endosc Percutan Tech, 2013, 23(2): 121-127.

31. Zhang X, Fu B, Lang B, et al. Technique of anatom- ical retroperitoneoscopic adrenalectomy with report of 800 cases. J Urol, 2007, 177(4): 1254-1257. PubMed

32. Karanikola E, Tsigris C, Kontzoglou K, et al. Laparoscopic adrenalectomy: where do we stand now? The Toboku Journal of experimental medicine, 2010, 220(4): 259-265. 33. Dalvi AN, Thapar PM, Thapar VB, et al. Laparoscopic adrenalectomy for large tumours: Single team experience. Journal of minimal access surgery, 2012, 8(4): 125-128. 34. Elfenbein DM, Scarborough JE, Speicher PJ, et al. Comparison of laparoscopic versus open adrenalectomy: results from American College of Surgeons-National Surgery Quality Improvement Project. The Journal of surgical research, 2013, 184(1): 216-220.

35. Hisano M, Vicentini FC, Srougi M. Retroperitoneoscopic adrenalectomy in pheochromocytoma. Clinics (Sao Paulo, Brazil), 2012, 67 Suppl 1161-167.

36.Gaujoux S, Bonnet S, Leconte M, et al. Risk factors for conversion and complications after unilateral laparoscopic adrenalectomy. The British Journal of Surgery, 2011, 98(10): 1392-1399.

37. Lombardi CP, Raffaelli M, De Crea C, et al. Endoscopic adrenalectomy: Is there an optimal operative approach? Results of a single-center case-control study. Surgery, 2008, 144(6): 1008 PubMed -1014; discussion 1014-1005.

38. Fiszer P, Toutounchi S, Pogorzelski R, et al. Laparoscopic adrenalectomy - assessing the learning curve. Polski przeglad chirurgiczny, 2012, 84(6): 293-297.

39. Dalvi AN, Thapar PM, Shah NS, et al. Has experience changed the scenario in laparoscopic adrenalectomy? The Indian Journal of Surgery, 2009, 71(2): 78-83.

40. Tiberio GA, Baiocchi GL, Arru L, et al. Prospective randomized comparison of laparoscopic versus open adrenalectomy for sporadic pheochromocytoma. Surgical endoscopy, 2008, 22(6): 1435 PubMed -1439.

41. Castillo O, Sanchez-Salas R, Vidal I. Laparoscopic adrenalectomy. Minerva urologica e nefrologica $=$ The Italian Journal of Urology and Nephrology, 2008, 60(3): 177-184.

42. Zaki FM, Osman SS, Abdul Manaf Z, et al. The value of pre-operative embolisation in primary inferior vena cava paraganglioma. The Malaysian Journal of Medical Sciences: MJMS, 2011, 18(2): 70-73. PubMed 